\title{
PRESCRIÇÕES MÉDICAS PARA AÇÕES JUDICIAIS
}

\author{
MEDICAL PRESCRIPTIONS FOR LAWSUITS
}

\section{Antonio Carlos da Ponte}

\begin{abstract}
Mestre, Doutor e Livre-Docente em Direito pela PUC-SP; Diretor da Escola Superior do Ministério Público de São Paulo (CEAF-ESMP); Professor da Graduação e da Pós-Graduação em Direito da PUC-SP e da Universidade Santa Cecília; Procurador de Justiça do Ministério Público de São Paulo. Email: silvanarsantos@mpsp.mp.br
\end{abstract}

Reynaldo Mapelli Júnior

Doutor em Ciências pela Faculdade de Medicina da Universidade de São Paulo (FMUSP); Assessor do Centro de Estudos e Aperfeiçoamento Funcional da Escola Superior do Ministério Público (CEAF-ESMP); Promotor de Justiça do Ministério Público do Estado de São Paulo.

Email: reynaldomj@uol.com.br

Recebido em: 06/11/2018

Aprovado em: 24/04/2019

RESUMO: Na análise da judicialização da saúde no Brasil, raramente se atenta para a centralidade das prescrições médicas usadas nos processos judiciais, faltando mesmo uma adequada compreensão jurídica de seus requisitos formais e materiais. Documento essencial da relação entre o médico e o paciente que possibilita ações e serviços da saúde, a prescrição médica deve cumprir formalidades mínimas de validade, com a identificação do paciente, do profissional e do local de atendimento, bem como das características do tratamento proposto, que deve respeitar a legislação sanitária, os protocolos clínicos, o tipo de receituário e a proibição de marca comercial de produto fármaco. Do ponto de vista material, a prescrição deve cumprir princípios éticos (autonomia do paciente, beneficência, não-maleficência e justiça) e não pode estar vinculada a qualquer vantagem econômica ou pessoal do prescritor, profissional que tem a obrigação de declarar conflito de interesse por relação com a indústria fármaco-hospitalar. Diante disso e conhecendo as estratégias ilícitas da indústria para vender medicamentos e procedimentos, frequentemente sem ganho terapêutico, como comprovado em literatura científica especializada, cabe ao magistrado agir com cautela na avaliação de pedidos liminares e determinar instrução probatória para verificar o princípio ativo dos medicamentos, o atendimento dos protocolos, a existência de registro ou autorização sanitária e a possibilidade de configuração de pesquisa clínica ou procedimento experimental, hipóteses que dependem do cumprimento de regras próprias. Casos excepcionais devem ser justificados pelos médicos, possíveis se comprovados o registro na ANVISA e a incapacidade econômica do paciente, como consagrado na jurisprudência. A exigência dos requisitos formais e materiais da prescrição médica, ao final, permite afastar escusos interesses econômicos e atender ao que realmente importa, que é o melhor tratamento para o paciente-autor. 
Palavras-chave: Judicialização da saúde; prescrição médica; ética; princípio ativo de medicamentos; protocolos clínicos e diretrizes terapêuticas; indústria fármaco-hospitalar

\begin{abstract}
In Brazil's health judicialization analysis, it is rarely looked to the central importance of medical prescription used in legal actions, lacking even an appropriate legal understanding of its formal and material requirements. The medical prescription, which enables practices and health services, is an essential document of the relationship between physician and patient and it must comply validity minimum conditions, as patient's and physician's identification, medical attendance determination as well as recommended treatment's characteristics, which must respect sanitary legislation, clinical protocols, prescription category and drug's commercial trademark prohibition. Materially, prescription must comply ethical requirements (patient's autonomy, beneficence, non-maleficence and justice) and its content must not be linked to any economic or personal benefit for the prescribing physician, which has the obbligation to declare conflicting interests on account of the eventual relationship with pharmaceutic industry. As a consequence, and knowing pharmaceutic industry illegal strategies to sell medicines and medical procedures, frequently without therapeutic advantage as proved in scientific specialised literature, it's up to the judge act with caution when evaluating preliminary injuctions and determining the discovery phase to verify the drug's active principle, the protocol observance, the sanitary registration or authorisation existence and the configuration of clinical research or experimental procedure, hypothesis that depend on the observance of specific rules. Exceptional cases must be justified by physicians if attested the ANVISA registration and patient's economic powerlessness, as many times affirmed in jurisprudence. The medical prescription formal and material preconditions requirement, in fact, allows to put away dubious economic interests and to attend what really matters, which is the best treatment for the author-patient.
\end{abstract}

Keywords: health judicialization; medical prescription; ethics; medicine active principle; clinical protocols and therapeutic statements; pharmaceutic and hospitalar industry.

SUMÁRIO: 1 Direito à saúde e intervenção do Poder Judiciário; 2 Prescrição Médica: Aspectos Formais; 3 Prescrição Médica e Ética; 4 Influência da Indústria Fármaco-Hospitalar; 5 Prescrição Médica, Protocolos Clínicos e Diretrizes Terapêuticas; 6 Casos Excepcionais; Conclusão; Referências.

\title{
1 DIREITO À SAÚDE E INTERVENÇÃO DO PODER JUDICIÁRIO
}

No sistema constitucional brasileiro, a saúde de todos os que moram no Brasil, sem qualquer distinção de condição econômica ou social, é direito fundamental que pode e deve ser exigido do Poder Público (arts. $6^{\circ}$ e 196, CF), que é o responsável pelas políticas públicas sanitárias formuladas para concretizar o acesso universal e igualitário à assistência (art. 196, CF) e o atendimento integral dos usuários (art. 198, inciso II, CF). Na prática, tal desiderato se dá pela implementação progressiva de uma rede interfederativa de serviços públicos hierarquizados, regionalizados e organizados, que incluem aqueles conveniados ou contratados da iniciativa privada (art. 199, $§ 1^{\circ}, \mathrm{CF}$ ), que constituem o SUS, o Sistema Único de Saúde (art. 198, caput, CF). 
Assim, quando há falta ou deficiência na assistência terapêutica buscada no sistema público de saúde como definido na Constituição da República, independentemente da possibilidade destes serviços serem proporcionados pela saúde suplementar ou privada (planos de saúde ou pagamento direito, que se submetem a outros regimes jurídicos), o usuário do SUS pode acionar o Poder Judiciário para que o seu direito à saúde seja concretizado, hipótese basilar de acesso à Justiça que permite compreender adequadamente o princípio da inafastabilidade da jurisdição, expressão máxima da cidadania em um Estado Democrático de Direito que respeita os direitos humanos (art. $5^{\circ}$, inciso XXXV, CF).

Desde o julgamento Pet. 1246/MC/SC, de 31 de janeiro de 1997, porém, por meio do qual o STF (Supremo Tribunal Federal) determinou ao SUS o financiamento de um tratamento experimental de transplante de células para um menino que tinha Distrofia Muscular de Duchenne, uma doença degenerativa rara incurável, em uma instituição privada nos Estados Unidos - ocasião em que ficou famoso o posicionamento do Ministro Relator Celso de Mello, segundo a qual "entre proteger a inviolabilidade do direito à vida (...) ou fazer prevalecer um interesse financeiro e secundário do Estado", "razões de ordem ético-jurídica impõem ao julgador uma só e possível opção: o respeito à vida" ${ }^{1}$ - , houve uma expressiva amplificação da ingerência do Poder Judiciário em assuntos de saúde. Na realidade, atualmente já há certo consenso jurídico sobre o excesso de demandas judiciais de saúde no Brasil, que obrigam independentemente do preço ao fornecimento das mais diversas prestações sanitárias, como tratamentos de alta complexidade e medicamentos de alto custo, fenômeno impressionante da sociedade moderna brasileira que chamou a atenção da comunidade internacional. ${ }^{2}$

Embora nos últimos anos alguns juristas tenham formulado críticas à judicialização da saúde, especialmente depois de alguns estudos que analisaram estatisticamente as consequências das ordens judiciais no limitado orçamento público do SUS e na organização dos serviços públicos de saúde ${ }^{3}$, propondo medidas para a racionalização da intervenção judicial, como defende o CNJ (Conselho Nacional de Justiça) desde a histórica audiência pública $\mathrm{n}^{\circ} 4$ do STF de abril e maio de 2009 - apoio técnico aos juízes (Recomendação CNJ nº 31/2010), criação de Varas Especializadas de Saúde Pública (Resolução CNJ no 238/2016) e uniformização de interpretações em enunciados elaborados nas Jornadas de Direito à Saúde do Fórum Nacional de Saúde - , há um aspecto fundamental que ainda carece de análise mais minuciosa: a centralidade da prescrição médica nas ações judiciais.

De fato, se nas ações judiciais quase sempre há uma prescrição médica para embasar um pedido de liminar ou tutela de urgência/evidência, frequentemente concedidos sem maiores aprofundamentos, ou para fundamentar a condenação definitiva em sentença, sendo esperado e defendido por muitos o acolhimento pelo julgador do diagnóstico e do prognóstico do profissional médico que fez a anamnese do paciente até prova em contrário - atividades privativas do médico,

\footnotetext{
${ }^{1}$ FERRAZ OLM. Harming the poor through social rights litigation: lessons from Brazil. Texas Law Review, University of Texas: EUA, 2011; 89:1643-1668.

${ }^{2}$ YAMIN AE e GLOPPEN S (editores). Litigating health rights: can courts bring more justice to health? Human Rights Series/Harvard Law School: EUA. Cambridge, MA: Harvard University Press, 2011.

${ }^{3}$ MAPELLI JÚNIOR R. Judicialização da saúde: regime jurídico do SUS e intervenção na administração pública. Rio de Janeiro: Atheneu, 2017; BORGE DCL e UGÁ MAD. Conflitos e impasses da judicialização na obtenção de medicamentos: as decisões de $1^{\text {a }}$ instância nas ações individuais contra o Estado do Rio de Janeiro, Brasil, em 2005. Cad Saúde Pública, Rio de Janeiro, 2010 janeiro, 26(1): 59-69; CHIEFFI AL e BARATA RCB. Judicialização da política pública de assistência farmacêutica e equidade. Cad Saúde Pública, Rio de Janeiro, 2009, 25(8):1839-1849; e BARROSO LR. Da falta de efetividade à judicialização excessiva: direito à saúde, fornecimento gratuito de medicamentos e parâmetros para a atuação judicial. Rev Jus UNIJUS, Universidade de Uberaba e Ministério Público do Estado de Minas Gerais, 2008 novembro, 11(15): 13-38.
} 
como se sabe (art. $4^{\circ}$, incisos II a VII, e $\S 1^{\circ}$, da Lei $n^{\circ} 12.842$, de 10 de julho de 2013) -, não parece razoável imaginar que documento tão importante não tenha requisitos de conformação, que devem obrigatoriamente ser observados pelo juiz de direito.

Compreender a prescrição médica juridicamente, em seus aspectos éticos e legais, para que seja aceita como prova lícita em processos judiciais, dessa forma, é tarefa primordial na distribuição da Justiça.

\title{
2 PRESCRIÇÃO MÉDICA: ASPECTOS FORMAIS
}

Como a prescrição é documento essencial da relação entre o médico e o paciente que permitirá acesso à saúde e procedimentos terapêuticos de relevância pública (art. 197, CF), há que se reconhecer antes de mais nada que possui formalidades mínimas de validade: não pode haver dúvida quanto ao seu conteúdo, que deve ser lícito e compreensível para o doente e para todos aquelas que dela se servirão - lembre-se seu caráter consumerista (art. $2^{\circ}$ caput, Código de Defesa do Consumidor - Lei $\mathrm{n}^{\circ} 8.078$, de 11 de setembro de 1990) - , como ocorre frequentemente com os farmacêuticos.

O Conselho Regional de Medicina do Estado de São Paulo, por isso, na Resolução CREMESP n $^{\circ} 278$, de 23 de setembro de 2015 estabeleceu quais são os requisitos mínimos da prescrição médica, para que sejam respeitados os princípios éticos da prática médica e a legislação sanitária:

\begin{abstract}
Artigo. $1^{\circ}$. A prescrição médica de medicamentos deve obedecer aos seguintes critérios mínimos: Letra legível ou por meio impresso; Nome completo do paciente; Nome genérico das substâncias prescritas; Forma farmacêutica do medicamento; Forma de administração de maneira clara; Não utilização de códigos ou abreviaturas; Observância quanto a presença do medicamento no protocolo do serviço o qual está vinculado; Data, nome legível, assinatura e número de registro do médico no Conselho Regional de Medicina; Nome e endereço da Instituição ou Consultório onde foi emitida a receita médica (g.n.).
\end{abstract}

Note-se que a maior preocupação é a de que o documento não contenha palavras ou expressões que possam causar dúvidas, como abreviaturas e escrita manual incompreensível, tenha origem certa quanto ao profissional responsável e unidade de saúde e não expresse nenhum comprometimento ético: por isso a obrigatoriedade de nome genérico do medicamento (princípio ativo), indicação de fórmula farmacêutica e modo de administração, e observância dos protocolos clínicos do serviço.

Esse deve ser o raciocínio inclusive se a prescrição preconizar procedimentos terapêuticos, ainda que desacompanhados de assistência farmacêutica, porque à semelhança dos medicamentos existem no mercado métodos diagnósticos, órteses, próteses, materiais e equipamentos de marca comercial diferenciada, não podendo ser escolhidos por interesse comercial ou pessoal.

O Manual de orientações básicas para a prescrição médica, formulado pelo Conselho Federal de Medicina e pelo Conselho Regional de Medicina do Estado da Paraíba em 2009, acrescenta ainda alguns elementos essenciais que não pode faltar em uma prescrição médica:

1. Cabeçalho - impresso, inclui nome e endereço do profissional ou da instituição onde trabalha (clínica ou hospital), registro profissional e número de cadastro de pessoa física ou jurídica, podendo conter, ainda, a especialidade do profissional; 
2. Superinscrição - constituída por nome e endereço do paciente, idade, quando pertinente, e sem a obrigatoriedade do símbolo $\mathrm{R}_{\mathrm{X}}$, que significa "receba"; por vezes, esse último é omitido, e no seu lugar se escreve: "uso interno" ou "uso externo", correspondente ao emprego de medicamentos por vias enterais ou parenterais, respectivamente;

3. Inscrição - compreende o nome do fármaco (denominação genérica ou princípio ativo), a forma farmacêutica e sua concentração.

4. Subinscrição - designa a quantidade total a ser fornecida; para fármacos de uso controlado, essa quantidade deve ser expressa em algarismos arábicos, escritos por extenso, entre parênteses;

5. Adscrição - é composta pelas orientações do profissional para o paciente;

6. Data, assinatura e número de inscrição no respectivo Conselho de Medicina, Medicina Veterinária ou Odontologia.

O receituário pode incluir, facultativamente, peso, altura e dosagens específicas como as usadas na pediatria, de acordo com a referida norma, e o seu verso pode ser utilizado para dar continuidade à prescrição, para o aprazamento de consulta de controle, e para as orientações de repouso, dietas, possíveis efeitos colaterais ou outras informações referentes ao tratamento.

Como há necessidade de controle sanitário dos medicamentos, de acordo com suas características e potencial lesividade ao usuário, o Manual segue a legislação sanitária para descrever os tipos de receituários que devem ser usados:

- Receita Simples - utilizada para a prescrição de medicamentos anódinos e medicamentos de tarja vermelha, com os dizeres "venda sob prescrição médica", segue as regras descritas na Lei n ${ }^{\circ} 5.991 / 73$. A duração do tratamento deve ser definida pelo médico de acordo com o perfil de cada patologia. É recomendado, no máximo, uma avaliação médica a cada 12 (doze) meses, dependendo da patologia, para prescrição de medicamentos de uso contínuo.

- Receita de Controle Especial - utilizada para a prescrição de medicamentos de tarja vermelha, com os dizeres "venda sob prescrição médica - só pode ser vendido com retenção da receita", como substâncias sujeitas a controle especial (validade da prescrição: 30 dias), retinoicas de uso tópico (lista "C2" - quantidade: 5 ampolas por medicamento injetável, com prazo de tratamento de 30 dias); antiretrovirais (lista "C4" - formulário próprio estabelecido pelo Programa de Doenças Sexualmente Transmissíveis/AIDS); anabolizantes (receituário de acordo com a Lei n ${ }^{\circ}$ 9.965/00; antidepressivos (listas "C" quantidade máxima: 5 ampolas para medicamentos injetáveis para 60 dias de tratamento); antiparkinsonianos e anticonvulsivantes (para 6 meses de tratamento), imunossupressoras (lista "C"), etc.

OBS: Os medicamentos antimicrobianos, segundo dispõe a RDC 44/2010, da ANVISA, que regulamenta a prescrição de 93 antimicrobianos, devem ter receitas (ou formulários) de controle especial ou comum, em duas vias, com validade de 10 dias a partir de sua emissão.

- Receita azul ou receita B - impresso, padronizado na cor azul, utilizado para a prescrição de medicamentos que contenham substâncias psicotrópicas, segundo as listas "B1" (quantidade máxima: 5 ampolas para medicamento injetável para 60 dias de tratamento) e "B2"(quantidade máxima: 30 dias de tratamento) e suas atualizações constantes na Portaria no $344 / 98$.

- Receita amarela ou receita A - impresso, padronizado na cor amarela, utilizado para a prescrição dos medicamentos das listas "A1", "A2" (entorpecentes) e "A3" (psicotrópicos), que somente pode conter um produto farmacêutico (validade da prescrição: 30 (trinta) dias). 
A preocupação com a lisura da prescrição dos fármacos, que devem ser identificados por denominação genérica ou princípio ativo e seguir os protocolos clínicos onde o paciente será tratado, tem especial importância em nosso ordenamento jurídico porque, ao contrário do que alguns pensam, há expressa vedação na lei de opção por produtos específicos: é direito básico do consumidor a faculdade de opção da terapia mais barata quando existente (art. $6^{\circ}$, incisos II e III, e arts. 39 a 41, CDC), direito da Administração Pública a promoção de licitação dos produtos disponíveis no mercado para uma devida concorrência que permita atender o maior número de doentes (a rigor, dever: art. 37, caput, CF e Lei no 8.666, de 21 de junho de 1993) e, no caso do SUS, a Lei ${ }^{\circ}$ 9.787, de 10 de fevereiro de 1990, que alterou a lei nacional de vigilância sanitária (Lei $\left.\mathrm{n}^{\circ} 6.360 / 76\right)$, textualmente proíbe a escolha por marca comercial:

Artigo. $3^{\circ}$. As aquisições de medicamentos, sob qualquer modalidade de compra, e as prescrições médicas e odontológicas de medicamentos, no âmbito do Sistema Único de Saúde - SUS, adotarão obrigatoriamente a Denominação Comum Brasileira (DCB) ou, na sua falta, a Denominação Comum Internacional (DCI).

Dessa forma, como ato essencial da relação médico-paciente que dá acesso à saúde e possibilita o recurso terapêutico adequado, que não pode ser corrompido por interesses comerciais e ilícitos, a prescrição médica deve respeitar os requisitos formais e de conteúdo, inclusive a escolha de fármaco por princípio ativo de acordo com os protocolos clínicos e a identificação do profissional responsável e da unidade de saúde a que está vinculado, sob pena de ser qualificada como meio ilícito de prova para o processo civil, ex vi do art. 396 do Código de Processo Civil.

\section{PRESCRIÇÃO MÉDICA E ÉTICA}

Do ponto de vista material, nada mais equivocado do que imaginar que a prescrição possa conter produtos e serviços sem base científica e com possibilidade de previsível risco à saúde do paciente, especialmente quando se nota os dilemas que envolvem a rápida evolução das pesquisas em seres humanos e das tecnologias em saúde e o alto custo para sua sustentabilidade. A atividade médica, por certo, não é ato isolado e absoluto, divorciado de princípios éticos e evidências científicas.

Em qualquer situação a decisão do médico deve atender rigorosamente aos princípios de defesa da vida humana, animal e vegetal que constituem a coluna vertebral do que se convencionou chamar de Bioética, um neologismo da década de 1970 (bios, vida + ethos, ética, em grego) primeiramente usado pelo pastor protestante alemão Paul Max Fritz Jahr, para uma ciência interdisciplinar que recorre à filosófica, à religião, ao direito, às ciências biológicas e outros conhecimentos correlatos, para discutir a ética nos procedimentos terapêuticos.

E não se pode esquecer, quanto a isso, os ensinamentos da história. De fato, embora a preocupação com a atuação ética tenha se feito presente já nos primórdios da ciência médica, com o grego Hipócrates da ilha de Kós (460 a 370 a.C.), que propunha uma visão naturalista das doenças em uma prática clínica no leito que devia conhecer os hábitos e as limitações de cada paciente ${ }^{4}$, as violações de direitos humanos ao longo da história a pretexto de desenvolvimento da ciência e correção de supostas deficiências humanas, no que foi emblemático o episódio dos médicos nazistas durante o holocausto na Segunda Guerra Mundial (1939 a 1945) - vinte deles foram

${ }^{4}$ BYNUM, W. História da medicina. Porto Alegre: L \& PM Pocket Editores, edição Oxforrd University Press, 2008, $15-28$. 
condenados no primeiro processo do Tribunal de Guerra de Nuremberg pelas experiências com judeus e outras minorias, inclusive o médico particular de Adolf Hitler, Karl Brandt, que recebeu pena de morte - , bem como as dúvidas advindas das possibilidades terapêuticas desenvolvidas pela indústria farmacêutica-hospitalar - como a manipulação genética, os remédios para pacientes idosos com doenças incuráveis ou graves, a redefinição sexual e as novas técnicas de abortamento - , ensejaram um posicionamento científico na atualidade que exige um plus na intervenção médica: o consentimento do paciente e o respeito à dignidade humana, como registrado na Declaração Universal sobre Bioética e Direitos Humanos (DUBDH) da UNESCO de 2005.

A prescrição, portanto, não pode agredir a dignidade humana, como frequentemente ocorre em pesquisas clínicas e tratamento experimental instalados sem a observância da legislação sanitária específica de regência, o que na prática se aufere mediante instrução probatória sobre os quatro princípios da Bioética que norteiam a atividade do bom médico: a-) autonomia do paciente, a concordância do doente, levando em consideração sua vontade e suas crenças; b-) beneficência, a garantia de que o procedimento terapêutico vai fazer bem; c-) não-maleficência, a garantia de que não causará danos injustificados; e d-) justiça, pensando-se que os custos e os benefícios devem ser distribuídos equitativamente. ${ }^{5}$

Some-se a isso o entendimento científico moderno no sentido de que, hoje em dia, a decisão do médico tem que estar fundamentada em evidência científica demonstrável, como proposto pela Medicina Baseada em Evidências (MBE), termo cunhado pelo pesquisador britânico Archie Cochrane na década de 1970, não podendo o profissional de saúde se basear em mera especulação; principalmente quando sua intervenção configura pesquisa em seres humanos e/ou terapia experimental, para os quais deve indicar expressamente o suporte científico utilizado, o médico deve colher o consentimento do paciente, garantir o financiamento da indústria interessada e submeter o protocolo de pesquisa à comissão de ética do hospital e à Comissão Nacional de Ética em Pesquisa (CONEP), como determinam a Declaração de Helsinki (com a Nota de Clarificação da 55 Conferência da Associação Médica Mundial de 2004) e a Resolução nº 466, de 12 de dezembro de 2012 do Conselho Nacional de Saúde.

O Código de Ética Médica (CEM) brasileiro, nesse passo, diz que o médico deve "indicar o procedimento adequado ao paciente" de acordo com o melhor avanço tecnológico disponível, mas "observadas as práticas cientificamente reconhecidas e respeitada a legislação vigente" (Resolução CFM n 1.931, de 17 de setembro de 2009, do Conselho Federal de Medicina, Capítulo II), o que certamente compreende o respeito aos protocolos de tratamento estabelecidos por "avaliação econômica comparativa dos benefícios e dos custos em relação às tecnologias já incorporadas, inclusive no que se refere aos atendimentos domiciliar, ambulatorial ou hospitalar, quando cabível” (art. 19-Q, §2º , inciso II, da Lei n 8.080/1990, a Lei Orgânica da Saúde), única forma de se garantir equidade em razão dos desafios ocasionados pelas mudanças advindas das transições demográficas e epidemiológicas - fluxo de migrantes, concentração da população em grandes centros urbanos, envelhecimento da população e prevalência das doenças crônicas, sem a extinção das infecciosas - e pelo encarecimento da tecnologia médica.

De outro lado, o Código de Ética Médica proíbe qualquer comercialização da medicina, que é uma ciência a serviço do ser humano (Capítulo I, I e IX, e art. 68), vedando ao médico especialmente: "praticar ou indicar atos médicos desnecessários ou proibidos pela legislação vigente no País" (art. 14); "exagerar a gravidade do diagnóstico ou do prognóstico, complicar a

\footnotetext{
${ }^{5}$ SANTORO, LF. Morte digna: o direito do paciente terminal. Curitiba: Juruá, 2010, pp. 101-105; e MARINO JUNIOR, R. Em busca de uma Bioética global: princípio para uma moral mundial e universal e de uma medicina mais humana. São Paulo: Hagnos, 2009, p. 81.
} 
terapêutica ou exceder-se no número de visitas, consultas ou quaisquer outros procedimentos médicos" (art. 35); "exercer a profissão com interação ou dependência de farmácia, indústria farmacêutica, óptica ou qualquer organização destinada à fabricação, manipulação, promoção ou comercialização de produtos de prescrição médica, qualquer que seja sua natureza"(art. 58); e "exercer simultaneamente a Medicina e a Farmácia ou obter vantagem pelo encaminhamento de procedimentos, pela comercialização de medicamentos, órteses, próteses ou implantes de qualquer natureza, cuja compra decorra de influência direta em virtude de sua atividade profissional" (art. 69).

O magistrado que se defronta com uma demanda em saúde, portanto, não pode ignorar que por trás dela podem exigir indesculpáveis interesses econômicos, devendo atentar para a lisura da prescrição médica e o respeito à dignidade dos pacientes, o que é atendido com o cumprimento da legislação sanitária, dos princípios éticos e dos esquemas de tratamento baseados em evidências científicas concretas.

\section{INFLUÊNCIA DA INDÚSTRIA FÁRMACO-HOSPITALAR}

O tema da ética médica demanda ainda algumas considerações complementares sobre a influência que laboratórios e indústria fármaco-hospitalar exercem sobre os médicos, na formação acadêmica, na atualização científica em congressos ou artigos e na prática profissional.

É claro que a liberdade profissional do médico devidamente registrado no Conselho Regional de Medicina do Estado em que trabalha, que tem base constitucional (art. $5^{\circ}$, inciso XIII, CF) e legal (Lei $n^{\circ} 12.842$, de 10 de julho de 2013), é condição essencial para que possa exercer a medicina "a serviço da saúde do ser humano e da coletividade", sendo-lhe facultado sempre "aprimorar continuamente seus conhecimentos e usar o melhor do progresso científico em benefício do paciente" (CEM, Capítulo I e V).

No processo judicial, porém, a autonomia do profissional médico não pode significar para o juiz de direito a impossibilidade de formulação de um juízo de valor a seu respeito. O magistrado não pode ser jungido a emprestar valor absoluto a uma prescrição médica, ficando, em virtude da magnitude do direito fundamental, obrigado ao deferimento de liminares ou julgar sem uma instrução probatória que permita analisar seu conteúdo, principalmente porque, como sabem os especialistas, atualmente a relação entre médicos e indústria vem gerando conflito de interesse que não podem mais ser ignorados.

No mundo contemporâneo são frequentes os conflitos de interesse de médicos, profissionais da saúde e gestores com algum tipo de vínculo com a indústria do setor farmacêutico-hospitalar no tratamento de pacientes, como reconheceu a ANVISA (Agência Nacional de Vigilância Sanitária) já em 2008, na regulamentação da publicidade de medicamentos no Brasil, ao proibir a vinculação de prescrição, dispensação ou publicidade de produtos fármacos a apoio ou patrocínio de eventos científicos nacionais ou estrangeiros, determinar a obrigatoriedade de comunicação expressa dos patrocínios no ato da inscrição dos participantes e nos anais dos congressos e eventos, e fixar a obrigatoriedade de informação clara sobre interesses por relação com laboratórios farmacêuticos ou outros de ordem natureza financeira ou comercial no início das palestras e nos documentos 
publicitários, providências que bem exemplificam o que vem ocorrendo (art. 42 da Resolução RDC $\mathrm{n}^{\circ} 96$, de 17 de dezembro de 2008). ${ }^{6}$

Já existe substanciosa literatura científica comprovando a relação íntima que se desenvolveu entre os médicos e a indústria fármaco-hospitalar dos bancos das faculdades aos congressos científicos, com evidente prejuízo para pacientes e sistemas de saúde. O marco histórico sobre isso, certamente, foi o livro A Verdade sobre os Laboratórios Farmacêuticos da médica norte-americana Márcia Angell, publicado em 2004, que denunciou a criminosa influência do setor industrial no meio acadêmico, nos consultórios médicos, nas organizações da sociedade civil e em escritórios de advocacia, para vender medicamentos e produtos, principalmente "medicamentos de imitação" com equivalentes terapêuticos bem mais baratos no mercado, como ocorreu entre os anos de 1998 e 2002 nos Estados Unidos. ${ }^{7}$

Em livro mais recente, o médico dinamarquês Peter C. Gotzche apresentou outra contundente denúncia sobre o tema, sustentando que o modelo assistencial com fins lucrativos subjacente à prática clínica atual, que pressupõe sempre benefícios econômicos e vantagens indevidas da indústria para os médicos, está errado e precisa ser enfrentado, porque a população vem sendo forçada a trocar medicamentos baratos por outros mais caros, frequentemente sem nenhum ganho terapêutico. ${ }^{8}$

Alguns artigos científicos comprovam com dados estatísticos as práticas ilícitas incentivadas pela relação médico-indústria, como sustentou Reynaldo Mapelli Júnior em obra sobre a judicialização da saúde, que foram aumentado ao longo dos anos: gastos muito mais expressivos em marketing do que em Pesquisa e Desenvolvimento (P\&D); propaganda abusiva em meios de comunicação e em sites de relacionamento da internet; financiamento de palestras e de publicação de artigos científicos escritos por ghostwriters; indução de mecanismos de convencimento de novos procedimentos terapêuticos e até mesmo de novas doenças (disease mongering); concessão de prêmios e benefícios a médicos; influência sobre as agências reguladoras; contribuição de dinheiro para associações representativas de doentes e grupos de advogados; concentração de medicamentos de alto custo em poucos advogados e médicos; e implementação de uma cultura de consumidores que são impulsionados a procurar informações diretas em sites, na mídia e em grupos sociais (escolas, empresas, organizações não governamentais, etc.) para ter acesso a drogas e produtos sem avaliação médica (biomedicalização da saúde)." 9

Tal situação levou o Conselho Regional de Medicina do Estado de São Paulo a regulamentar a relação do profissional médico com a indústria, na Resolução CREMESP nº 273, de 3 de fevereiro de 2015, ocasião em que reconheceu expressamente o seguinte: há evidências científicas de influência da indústria nas prescrições dos médicos; a participação dos profissionais patrocinada em congressos e eventos científicos é eticamente relevante; os gastos com publicidade dos laboratórios farmacêuticos e das indústrias de órteses e próteses e materiais são repassados ao preço final dos produtos; em muitas situações a relação do profissional com a indústria ultrapassa os limites éticos, bioéticos e sociais da boa prática; a prática médica está subordinada às normas legais, ao reconhecimento científico e aos princípios éticos e bioéticos, não sendo portanto destituída de

\footnotetext{
${ }^{6}$ MARQUES, AJS e DUTRA, RAA. Conflito de Interesse: Transparência para Ficar Legal. In Coletânea Direito à Saúde: Boas Práticas e Diálogos Institucionais, vol. 3, organizadores Alethele de Oliveira Santos e Luciana Tolêdo Lopes, Brasília (DF): CONASS, 2018, pp. 116;127.

${ }^{7}$ ANGELL M. A Verdade sobre os Laboratórios Farmacêuticos. Rio de Janeiro: Record, 2010.

${ }^{8}$ GOETZCHE, PC. Medicamentos mortais e crime organizado: como a indústria farmacêutica corrompeu a assistência médica. Porto Alegre: Bookman, 2016.

${ }^{9}$ MAPELLI JÚNIOR R., op.cit, pp. 168-169.
} 
parâmetros; as prescrições somente podem ser formuladas de acordo com as credenciais científicas dos produtos e as necessidades dos pacientes, devendo a decisão médica se pautar por diretrizes científicas e estudos de custo-efetividade quando houver mais de uma alternativa terapêutica disponível (no introito, nas "considerações" da norma). Assim, o CREMESP determinou que o profissional médico informe por escrito se foi contratado como speaker (consultor ou divulgador) ou se exerce outra atividade pela indústria fármaco-hospitalar, e declare expressamente o seu conflito de interesses em palestras patrocinadas pelo setor industrial, principalmente quando abordam eficácia terapêutica ou diagnóstica de produto ou medicamento. Além disso, proibiu a prescrição de medicamentos, órteses, próteses e materiais, ou o uso de métodos diagnósticos, mediante "contrapartidas como recebimento de gratificações, ou pagamento de inscrições em eventos e viagens, bem como qualquer outra forma de vantagem", e estabeleceu que "nos procedimentos que envolvem a colocação ou troca de órteses, próteses e materiais" fica proibida "a entrada na sala cirúrgica de representantes das empresas, exceto quando em função exclusivamente técnica e sem acesso ao campo cirúrgico".

A prescrição de produtos e materiais hospitalares e os conflitos de interesse foram objeto de específica preocupação do Conselho Federal de Medicina, que, na Resolução CFM n ${ }^{1.956}$, de 25 de outubro de 2010, fixou caber ao "médico assistente determinar as características (tipo, matéria-prima, dimensões) das órteses, próteses e materiais especiais implantáveis", bem como o “ instrumental compatível, necessário e adequado à execução do procedimento", já que o responsável pela operação médica, "observadas as práticas cientificamente reconhecidas e as legislações vigentes no país", sendo-lhe vedado porém "exigir fornecedor ou marca comercial exclusivos". Quando o médico oferecer à operadora de saúde ou instituição pública uma opção que entenda mais adequada, o que somente se justifica se a prescrição fundamentar bem a excepcionalidade, deve haver uma reavaliação por arbitragem por um outro especialista (arts. $1^{\circ}$, $3^{\circ}, 5^{\circ}$ e 6$)$.

Tudo isso aconselha o juiz de direito, ciente dos interesses econômicos que circundam o ato médico e da regulamentação da atividade do médico construída para que o vínculo com a indústria respeite preceitos éticos, a não aceitar acriticamente a prescrição, para deferir liminares ou tutelas de urgência/evidência de pronto, salvo impossibilidade fática que deve ser afirmada fundamentadamente (art. 93, inciso X, CF), devendo por cautela ouvir previamente o gestor de saúde acerca da possibilidade de atendimento espontâneo com eventual procedimento terapêutico substituto e outras informações técnicas correlatas, "preferencialmente por meio eletrônico" (Recomendação CNJ $n^{\circ} 31$, de3 0 de março de 2010). Depois da análise do pedido liminar, configurado o litígio pela discordância do pedido da ação, deve então o magistrado determinar instrução probatória, para ouvir os interessados e requisitar informações dos órgãos técnicos sobre os protocolos clínicos e as diretrizes terapêuticas, o princípio ativo dos medicamentos, o registro sanitário (Ministério da Saúde e Secretarias, Agência Nacional de Vigilância Sanitária e Comissão Nacional de Incorporação de Tecnologias no SUS) e a possibilidade do tratamento constituir pesquisa clínica ou procedimento experimental (Comissão Nacional de Ética em Pesquisa e Conselhos de Profissão), evitando escusos interesses econômicos e atendendo ao que realmente importa, que é o melhor tratamento para o paciente-autor. 


\section{PRESCRIÇÃO MÉDICA, PROTOCOLOS CLÍNICOS E DIRETRIZES TERAPÊUTICAS}

A prescrição médica também não pode se afastar dos esquemas de tratamento padronizados denominados protocolos clínicos, obrigação dos médicos reconhecida pela Resolução CREMESP n 278/15, como já mencionado, o que não representa uma restrição burocrática ao direito à saúde, mas medida imprescindível utilizada em todos os sistemas de saúde no mundo para que não haja desperdícios e discriminações.

Uma visão superficial do texto constitucional poderia sugerir que a diretriz de "atendimento integral, com prioridade para as atividades preventivas, sem prejuízo dos serviços assistenciais" (art. 198, inciso II, CF) significaria mesmo o dever do SUS em oferecer qualquer prestação positiva sanitária, bastando para tanto a prescrição de um médico, mas a ideia não subsiste a nenhuma análise econômica ou gestacional: isso é impossível em qualquer sistema de saúde, público ou privado, ainda que de países desenvolvidos. O próprio art. 198 da Constituição da República, na verdade, definiu o sistema público de saúde brasileiro como um conjunto organizado de serviços de serviços públicos, que devem constituir uma rede regionalizada (serviços em redes de atenção em saúde) hierarquizada (serviços de atenção básica, secundária ou terciária, com portas de entrada e fluxo de atendimento do mais simples ao mais complexo, segundo um sistema de referência e contrarreferência), com assistência descentralizada (levando-se gradualmente serviços federais e estaduais para a esfera municipal, todos com autonomia administrativa em sua esfera de governo) que respeita a participação da comunidade (controle social, especialmente pelos Conselhos de Saúde e Conferência de Saúde), não deixando espaço para esse tipo de pensamento.

Ora, a única forma de se organizar as políticas públicas de saúde para atingir a finalidade do Estado, com a limitação dos recursos orçamentários e os custos crescentes das tecnologias médicas, quando se pensa na universalização do direito à saúde que deve ser de todos e de acesso igualitário (art. 196, CF), é pela padronização das ações governamentais sanitárias em procedimentos técnicos administrativos que contenham os produtos e serviços disponíveis e o esquema de tratamento propugnado, o que se convencionou chamar no Brasil de Protocolos Clínicos e Diretrizes Terapêuticas (PCDT).

Lembre-se que a atuação do médico se submete à "regulamentação, fiscalização e controle" do Poder Público porque a "relevância pública" é característica essencial das ações e serviços de saúde (art. 197, CF), devendo obediência à padronização, ao controle de procedimentos, produtos e substâncias de interesse para a saúde, inclusive psicoativos, tóxicos e radioativos, e demais ações de vigilância sanitária e epidemiológicas tipicamente do SUS, que devem atingir todas as atividades que tocam a saúde das pessoas (art. 200, incisos I, II e VII, CF).

Os protocolos clínicos, presentes mesmo em hospitais e ambulatórios privados, representam padronização do tratamento segundo a lógica das evidências científicas e do custo-efetividade, para que todos possam ter acesso à assistência em saúde, condição organizacional dos serviços de saúde reconhecida pela OMS (Organização Mundial da Saúde) pelo menos desde 1978, quando, na Declaração de Alma-Ata formulada na antiga URSS, no Cazaquistão, definiu a centralidade dos cuidados primários de saúde para o acesso (porta de entrada) e o controle do processo contínuo de assistência de modo organizado, inclusive com uma lista nacional de medicamentos para as 
doenças mais comuns, posição reiterada na recente Declaração de Astana de 25 de outubro de 2018. 10

A própria Lei Orgânica da Saúde (Lei no 8.080, de 19 de setembro de 1990), na alteração da Lei $n^{\circ}$ 12.402/2011, definiu a assistência terapêutica integral como a (i) dispensação de medicamentos e produtos de interesse para a saúde, cuja prescrição esteja em conformidade com as diretrizes terapêuticas definidas em protocolo clínico para a doença ou o agravo à saúde a ser tratado ou, na falta do protocolo, em conformidade com o disposto no art. 19-P; e também (ii) o oferta de procedimentos terapêuticos, em regime domiciliar, ambulatorial e hospitalar, constantes de tabelas elaboradas pelo gestor federal do Sistema Único de Saúde - SUS, realizados no território nacional por serviço próprio, conveniado ou contratado (art. 19-M, incisos I e II, g.n.).

Os Protocolos Clínicos e Diretrizes Terapêuticas do SUS, formulados pelo Ministério da Saúde depois de análise da CONITEC (Comissão Nacional de Incorporação de Tecnologias no SUS), e outras listas de serviços e produtos elaborados na sua falta, que devem ser atualizados periodicamente segundo procedimento administrativo que tem forma e prazo certos (arts. 19-R, 19-T e 19-U, Lei Orgânica da Saúde, e Decreto no 7.646 de 21 de dezembro de 2011), não são por isso um obstáculo administrativo ao direto à saúde, mas constituem um mecanismo de caráter organizacional essencial para que o SUS atenda a todos os brasileiros. Isso se percebe, claramente, pelo conceito legal dos protocolos clínicos exposto na Lei Orgânica da Saúde, com seus critérios de formulação e atualização:

Art. 19-N. I: protocolo clínico e diretriz terapêutica: documento que estabelece critérios para o diagnóstico da doença ou do agravo à saúde; o tratamento preconizado, com os medicamentos e demais produtos apropriados, quando couber; as posologias recomendadas; os mecanismos de controle clínico; e o acompanhamento e a verificação dos resultados terapêuticos, a serem seguidos pelos gestores do SUS.

Art. 19-O. Os protocolos clínicos e as diretrizes terapêuticas deverão estabelecer os medicamentos ou produtos necessários nas diferentes fases evolutivas da doença ou do agravo à saúde de que tratam, bem como aqueles indicados em casos de perda de eficácia e de surgimento de intolerância ou reação adversa relevante, provocadas pelo medicamento, produto ou procedimento de primeira escolha.

Parágrafo único. Em qualquer caso, os medicamentos ou produtos de que trata o caput deste artigo serão aqueles avaliados quanto à sua eficácia, segurança, efetividade e custo-efetividade para as diferentes fases evolutivas da doença ou do agravo à saúde de que trata o protocolo.

O Decreto no 7.508, de 28 de junho de 2011, que regulamenta a Lei Orgânica da Saúde, na mesma linha de raciocínio estabeleceu critérios para o acesso e o tratamento na rede pública de saúde que, além da assistência em unidades públicas por meio de ações e serviços preceituados por profissional de saúde no exercício regular de funções do SUS, pressupõem "estar a prescrição em conformidade com a RENAME e os Protocolos Clínicos e Diretrizes Terapêuticas com a relação específica complementar estadual, distrital ou municipal de medicamentos" (art. 28, inciso III).

No Estado de São Paulo, no exercício de sua competência legal de regulamentação das atividades assistenciais e de controle dos serviços sanitários (art. 15, incisos VI e XVI, art. 17, incisos XI e XII e art. 18, inciso XII, LOS) em sua esfera de governo (art. 198, inciso I, CF), tanto o Secretário de Estado quanto o Secretário do Município da capital regulamentaram a prescrição médica para uso na rede pública, em termos que sinalizam a obrigatoriedade de observância dos

${ }^{10}$ BRASIL: Brasil: RENAME (Relação Nacional de Medicamentos Essenciais) e Programa de Saúde da Família (Portaria MS n ${ }^{\circ}$ 2.436, de 21 de setembro de 2.017). 
protocolos e dos produtos disponíveis, ficando vedada a indicação de fármacos sem registro na ANVISA e de procedimentos experimentais e/ou não previstos. $\mathrm{O}$ gestor estadual, de sua parte, fixou requisitos formais para a prescrição do médico da rede pública estadual, a necessidade de justificativa técnica e avaliação por instância superior quando a escolha recai em medicamentos não padronizados, de apresentação de declaração escrita de inexistência de conflito de interesses e a possibilidade de que os custos fiquem com a instituição onde o médico trabalha. Na mesma resolução, além disso, previu medidas para ressarcimento ao erário público "do custo de medicamento judicializado contra a Fazenda do Estado" (Resolução SS - 83, de 17 de agosto de 2015). Na regulamentação do Secretário Municipal de Saúde de São Paulo, para as receitas médicas usadas na rede municipal de serviços, que têm validade de 30 (trinta) dias, há que se observar a Relação Municipal de Medicamentos (REMUME), os padrões éticos como prescrição por denominação genérica, e um receituário padrão contendo informações técnicas mínimas (Portaria SMS.G n n 82 , de 5 de dezembro de 2015; o receituário padrão consta do Anexo 5).

A legislação sanitária, inclusive as normas administrativas, portanto, tornaram regra geral o dever de atenção aos protocolos clínicos e às diretrizes terapêuticas, não deixando dúvidas de que a observância dos esquemas de tratamento - inclusive inclusão na rede pública de atenção à saúde - é imposição ética que decorre do regime jurídico do SUS, o que não pode ser esquecido quando o documento médico é usado em processos judiciais, onde informações dos gestores do SUS (Ministério da Saúde e Secretarias Estaduais e Municipais) e dos órgãos fiscalizatórios (ANVISA, CONITEC e Comissão Nacional de Ética em Pesquisa, a CONEP), em instrução probatória robusta, são essenciais para garantir a equidade em saúde.

\section{CASOS EXCEPCIONAIS}

Como a medicina não é ciência exata e a prática clínica deve se adaptar às peculiaridades do quadro patológico do paciente, teoricamente podem ocorrer, porém, situações excepcionais de necessidade de acesso a medicamentos e procedimentos terapêuticos não previstos nos protocolos clínicos e nas diretrizes terapêuticas, como vem reconhecendo o SUS em algumas normas administrativas.

A despeito da definição legal de atendimento integral como dispensação de produtos e serviços previstos nos protocolos clínicos e nas listas oficiais de procedimentos terapêuticos (art. 19-M, LOS), de fato, a Comissão Intergestores Tripartite, órgão de negociação dos gestores do SUS em Brasília (art. 14-A e art. 19-U, LOS), autorizou a dispensação de medicamentos não padronizados se o médico preencher um formulário específico justificando a excepcionalidade com exames, demonstração de evidências científicas e informações sobre riscos e urgência, para avaliação técnica superior (Resolução CIT nº 29, de 26 de janeiro de 2017), como já havia feito anteriormente no Estado de São Paulo a Secretaria Estadual, embora com a possibilidade de custeio pela instituição hospitalar e ressarcimento do profissional médico que agir com má-fé (Resolução $\left.\mathrm{SS} \mathrm{n}{ }^{\circ} 83 / 15\right)$.

Esse é o entendimento, também, do Conselho Regional de Medicina do Estado de São Paulo, que permite ao médico prescrever medicamento fora do protocolo do serviço a que está vinculado - apesar de sua obrigação em segui-lo em princípio - justificadamente, em situações excepcionais, em relatório a ser entregue ao Diretor Técnico que pode convocar uma junta médica para deferir ou não o pedido, documento imprescindível também caso a prescrição seja utilizada no SUS para medicamento não previsto em suas listas oficiais (arts. $2^{\circ}, 3^{\circ}$ e $7^{\circ}$, da Resolução CREMESP nº 278/15). 
O Superior Tribunal de Justiça, fazendo uso da técnica de afetação de processos (art. 1.036, CPC) para analisar em conjunto todas demandas de medicamentos não padronizados no Brasil, no Recurso Especial no ${ }^{\circ}$.657.156 - RJ decidiu pela obrigatoriedade de fornecimento de medicamentos não incorporados no SUS em casos excepcionais, exigindo que o autor da ação comprove, cumulativamente, a imprescindibilidade do produto fármaco em comparação aos garantidos pela rede pública mediante laudo fundamentado de seu médico, sua incapacidade financeira de arcar com os custos e o registro na ANVISA, critérios nem sempre aceitos pela doutrina em razão da legislação sanitária ${ }^{11}$ mas que, enquanto não forem revisados pelo Supremo Tribunal Federal, são de obrigatória observância pelos magistrados (art. 1.040, CPC).

Desta forma, desde que o produto fármaco possua registro sanitário na ANVISA e o procedimento terapêutico não tenha natureza experimental (art. 19-T, incisos I e II, LOS e RE $\mathrm{n}^{\circ} 1.657 .156$ - RJ), a prescrição fora dos protocolos clínicos e diretrizes terapêuticas é possível, mas excepcionalmente e com boa justificativa técnica, devendo o médico elaborar um relatório que justifique a opção terapêutica, com um detalhamento da doença, do tratamento e seu tempo de duração, da imprescindibilidade do prescrito em relação ao já existente e da incapacidade financeira do usuário do SUS em custear o tratamento, circunstâncias factuais que certamente vão exigir uma instrução probatória para sua confirmação.

Tratando de excepcionalidades, não custa acrescentar que o próprio SUS possui via administrativa para acesso expandido a medicamentos únicos, mesmo se não forem registrados no Brasil, acesso a medicamentos pós-estudos e ao uso compassivo de drogas isoladas, nas hipóteses previstas na Resolução RDC (Resolução da Diretoria Colegiada) no 38, de12 de agosto de 2013, da ANVISA (Agência Nacional de Vigilância Sanitária). Fazendo uma interpretação sistemática desta norma com a Resolução CNS n 466/12 e Declaração de Hensinki, pode-se afirmar a possibilidade de acesso administrativo a produtos fármacos novos, com ou sem registro sanitário, desde que comprovados os seguintes requisitos: a) evidências científicas, consentimento do paciente, financiamento da indústria e aprovação nas comissões de ética locais e no Conselho Nacional de Ética em Pesquisa (CONEP), na hipótese de pesquisa clínica; b) nos demais casos (ausência de pesquisa), comprovação de que o medicamento é a única alternativa terapêutica viável para o tratamento de doenças com risco de morte ou debilidades graves, seja ele um produto novo ainda sem registro na ANVISA ou não disponível comercialmente no país, em estudo de fase III em desenvolvimento ou concluído (acesso expandido), seja um produto que estava sendo disponibilizado gratuitamente em pesquisa que foi encerrada ou da qual o paciente se desligou (medicamento pós-estudo), seja um medicamento novo promissor, para uso pessoal, de pessoa não participante de programa de acesso expandido, pós-estudo ou pesquisa clínica, que esteja em processo de desenvolvimento clínico e sem alternativa terapêutica no país.

Em processos judiciais, notadamente em razão da jurisprudência do STJ, portanto, para situações específicas que não podem ser banalizadas porque a Lei Orgânica da Saúde determina a integralidade dentro do sistema SUS (art. $7^{\circ}$, inciso II, in fine) como dispensação do medicamentos, produtos e procedimentos terapêuticos de acordo com os protocolos clínicos e as listas oficiais (art. 19-M, incisos I e II), a ser iniciada e completada na Rede de Atenção à Saúde (art. 20, Decreto no 7.508/11), é admissível prescrição médica de produtos e serviços não padronizados, desde que haja registro sanitário, inexistir alternativa terapêutica e o paciente-autor não tiver condições de financiar o tratamento.

\footnotetext{
${ }^{11}$ SANTOS L. Decisão do STJ sobre medicamento de alto custo deforma conceito do direito à saúde. Disponível em www.conjur.com.br. Acesso em 21.07.2018.
} 


\section{CONCLUSÃO}

Em conclusão, podemos afirmar sobre a prescrição médica usada nos processos judiciais, como prova lícita capaz de influenciar o convencimento do juiz (art. 371, CPC), o seguinte:

1) em regra, é documento essencial por representar a relação entre o médico e o paciente e constituir condição de acesso a ações e serviços de saúde;

2) quando instrui ação judicial em desfavor do Poder Público, deve ser elaborada por profissional de saúde no exercício regular de funções do SUS e para atendimento em unidades públicas de saúde, de acordo com os procedimentos técnicos de acesso e tratamento em uma rede de atenção à saúde do SUS, sob pena de redirecionamento da demanda para planos e operadoras de saúde;

3) deve respeitar requisitos formais de elaboração e conteúdo, como exigido pelos conselhos de medicina, com a indicação do profissional responsável e local em que foi emitida, nome completo do paciente, nome genérico dos produtos farmacêuticos com as doses e periodicidade do tratamento, descrição dos procedimentos terapêuticos e a afirmação expressa de que segue os protocolos clínicos e as diretrizes terapêuticas;

4) deve cumprir os princípios éticos (autonomia, beneficência, não-maleficência e justiça) e não pode estar vinculada a qualquer vantagem econômica ou benefício pessoal do prescritor, profissional que tem a obrigação de declarar se possui conflito de interesse e relação com a indústria fármaco-hospitalar e se isso foi comunicado previamente ao Conselho Regional de Medicina;

5) não pode, jamais, optar por determinada marca comercial, mas apontar a denominação genérica (princípio ativo) para o exercício do direito de escolha do paciente e o dever de aquisição mais barata pelo SUS (princípio da licitação);

6) deve vir acompanhada de relatório médico circunstanciado com informações complementares, para avaliação se o produto e o procedimento terapêutico possuem registro ou autorização sanitária, se constitui pesquisa clínica, tratamento operacional ou depende de importação, e se existe alternativa terapêutica substituta nos protocolos clínicos e listas oficiais;

7) quando indica medicamento ausente nas políticas públicas do SUS, deve vir acompanhada de justificativa técnica (relatório medico) demonstrando a imprescindibilidade do produto fármaco em comparação aos garantidos pela rede pública e prova da incapacidade financeira do autor-paciente arcar com os custos, sendo imprescindível o registro na ANVISA;

8) quando seu conteúdo for objeto de discordância do réu, deve ensejar obrigatoriamente uma adequada instrução probatória, com a ouvida do médico e do paciente, a realização de perícia médica e a colheita de informações técnicas dos órgãos competentes, especialmente dos gestores públicos (Ministério da Saúde e Secretarias) e privados (planos e operadoras de saúde) responsáveis pela assistência e das instituições responsáveis pelo registro (ANVISA), inclusão de tecnologias (CONITEC e Agência Nacional de Saúde Suplementar) e controle de pesquisas e experimentos (CONEP), bem como de esclarecimentos específicos dos conselhos de profissão, associações médicas de especialistas, centros de medicina baseada em evidências e universidades;

9) se configurar uma infração ética às normas administrativas que regulamentam a atividade médica, o ato médico deve ser comunicado ao Conselho Regional de Medicina, requisitando-se a instauração de inquérito policial se houver suspeita de prática criminosa. 


\section{REFERÊNCIAS}

ALEXY, Robert. Teoria dos Direitos fundamentais. Trad. Virgílio Afonso da Silva. São Paulo, Malheiros Editores, 2008.

ANGELL, M. A verdade sobres os laboratórios farmacêuticos. Rio de Janeiro, Record, 2010.

BARROSO, Luís Roberto. Interpretação e aplicação da Constituição. $7^{a}$ ed. São Paulo, Saraiva, 2009.

BASTOS, Celso Ribeiro. Hermenêutica e Interpretação Constitucional. São Paulo, Celso Bastos Editora, 2002.

BYNUM, W. História da Medicina. Porto Alegre. L \& M Pocket Editores, edição Oxford University Press, 2008.

DINIZ, Maria Helena. O Estado atual do Biodireito. 10ª ed. São Paulo, Saraiva, 2017.

FERRAZ OLM. Harming the poor trough social rights litigation: lessons from Brazil. Texas Law Review, University of Texas: EUA, 2011.

GARCIA, Maria. Limites da Ciência: A dignidade da pessoa humana. A ética da responsabilidade. São Paulo, Revista dos Tribunais, 2004.

GOETZCHE, P. C. Medicamentos mortais e crime organizado: Como a indústria farmacêutica corrompeu a assistência médica. Porto Alegre, Bookman, 2016.

MAPELLI JÚNIOR, Reynaldo. Judicialização da Saúde: Regime jurídico do SUS e intervenção na Administração Pública. Rio de Janeiro, Atheneu, 2017.

KRAUT, Alfredo Jorge. Los Derechos de los pacientes. Buenos Aires, Abeledo-Perrot, 1997.

MARINO JÚNIOR, R. Em busca de uma Bioética global: Princípio para uma moral mundial e universal e de uma medicina mais humana. São Paulo, Hagnos, 2009.

PONTE, Antonio Carlos da. MAPELLI JÚNIOR, Reynaldo. Redes interfederativas de serviços de saúde e controle do Ministério Público: O papel dos Estados no SUS. In: Revista de Direito Brasileiro, v. 18, n. 7, p. 315-330 (Set./Dez. 2017).

SANTORO, Luciano F. Morte digna: O direito do paciene terminal. Curitiba, Juruá, 2010.

YAMIN AE e GLOPPEN S (editores). Litigating health rights: can courts bring more justice to health? Human Rights Series/Harvard Law School: EUA. Cambridge, MA: Harvard University Press, 2011. 